\title{
A New Classification for Ankle Arthrodesis When Using an External Fixator
}

\author{
Hidenori Matsubara ${ }^{1}$, Koji Watanabe ${ }^{2}$, Munetomo Takata ${ }^{3}$, Issei Nomura ${ }^{4}$, Hiroyuki Tsuchiya ${ }^{5}$
}

\begin{abstract}
Background: We have classified ankle arthrodesis when using an external fixator into four types based on the deformity and defect. Each of the four types of technique have been evaluated retrospectively.

Materials and methods: Thirty-three lower limb segments in 30 patients (average age 49 years) were treated by ankle arthrodesis using an external fixator in our institution. We classified the pre-treatment problems into four types and adjusted the surgical treatment accordingly: type I-no bone defect, no or mild deformity; type II—no bone defect, severe deformity; type III—bone defect with the possibility to shorten acutely after resection of the pathological focus; and type IV - bone defect but without the ability to shorten acutely after resection of the pathological focus. Type I problems were treated with curettage of ankle cartilage and bone graft with external fixation. Type II problems were treated with mobilisation using an external fixation after performing a type I ankle arthrodesis. Type III problems were treated with ankle arthrodesis using acute shortening and distraction. Type IV problems were treated with ankle arthrodesis using bone transport.

Results: All patients had secure ankle fusion and were able to bear total weight in walking on completion of treatment. The mean external fixation period was 96 days in type I, 181 days in type II, 231 days with lengthening in type III and IV. The complications included re-fracture in three cases, deformity at the lengthening site in one, delayed union in one, and infection at fusion site in one.

Conclusion: We have strategized ankle arthrodesis procedures using an external fixator into four groups in order to align the surgical technique with the pre-treatment problem. Our classification can help decide the appropriate operative method when using an external fixator, especially for difficult cases.

Keywords: Ankle arthrodesis, Bone defect, Classification, Deformity, External fixation.

Strategies in Trauma and Limb Reconstruction (2019): 10.5005/jp-journals-10080-1436
\end{abstract}

\section{INTRODUCTION}

Ankle arthrodesis is used for end stage ankle arthritis and is an operation suited when the problem is resistant to conservative treatment. There are several operative methods of ankle arthrodesis using different fixation techniques and surgical approaches but no single one is optimum for the variety of presentations of the clinical problem. Each procedure has each benefits and demerits. Recently, reports on arthroscopic ankle arthrodesis are gaining popularity because of minimal invasiveness but the indication is limited. ${ }^{1-3}$ Similarly, there are recent papers on ankle arthrodesis using an external fixator for complex cases due to the versatility of the technique. ${ }^{4-12}$

The availability of several options in performing an ankle arthrodesis suggests that there is no one perfect way but, in recognition of the fact there are variable presentations and aetiologies to end-stage ankle arthritis, it is relevant to choose the optimum operative method for each patient. In our institute, we have been using a ring external fixator for the patients who in need of an ankle arthrodesis since 1993. We note there are no previous reports describing the kinds and methods of ankle arthrodesis when using an external fixator.

In this study we propose a classification of the operative methods of ankle arthrodesis when using an external fixator and report the indication, strategy, advantages, and disadvantages of each type of ankle arthrodesis.

\section{Materials and Methods}

Between 1993 and 2011, 33 ankles of 30 patients (19 men and 11 women) requiring ankle arthrodesis were treated in our institute (Table 1). The mean age of the patients was 49.6 years
${ }^{1-5}$ Department of Orthopaedic Surgery, Kanazawa University, Takaramachi, Kanazawa, Japan

Corresponding Author: Hiroyuki Tsuchiya, Department of Orthopaedic Surgery, Kanazawa University, Takaramachi, Kanazawa, Japan, Phone: +81-76-265-2374, e-mail: tsuchi@med.kanazawa-u.ac.jp

How to cite this article: Matsubara $\mathrm{H}$, Watanabe $\mathrm{K}$, Takata $\mathrm{M}$, et al. A New Classification for Ankle Arthrodesis When Using an External Fixator. Strategies Trauma Limb Reconstr 2019;14(3):148-154.

Source of support: Nil

Conflict of interest: None

(18-82). Informed consent was obtained from each patient before enrolment and the study was approved by the Institutional Review Board of the university hospital. The average follow-up period was 46.5 months (7 to 188). The aetiologies were suppurative ankle arthritis or osteomyelitis for 11 ankles, paralytic equinus foot for nine ankles, primary osteoarthritis for four ankles, secondary osteoarthritis for three ankles, a pilon fracture with large bone loss for three ankles, the Charcot joint in two ankles, and rheumatoid arthritis for one ankle. Tibiotalar fusion was performed in 23 ankles, tibiotalocalcaneal fusion in six ankles, and tibiocalcaneal fusion in four ankles. We used the llizarov external fixator in 20 ankles between 1993 and 2002, and subsequently the Taylor Spatial Frame in 13 ankles since 2003. The Taylor Spatial Frame is a type of ring shaped external fixator, consists of two rings, and six struts which are expandable (hexapod). It can, using software guidance, correct all components of deformity simultaneously: angulation, translation, rotation, elongation, and shortening. ${ }^{13}$ Since 2013 we

(c) The Author(s).2019 Open Access This article is distributed under the terms of the Creative Commons Attribution 4.0 International License (https://creativecommons. org/licenses/by-nc/4.0/), which permits unrestricted use, distribution, and non-commercial reproduction in any medium, provided you give appropriate credit to the original author(s) and the source, provide a link to the Creative Commons license, and indicate if changes were made. The Creative Commons Public Domain Dedication waiver (http://creativecommons.org/publicdomain/zero/1.0/) applies to the data made available in this article, unless otherwise stated. 


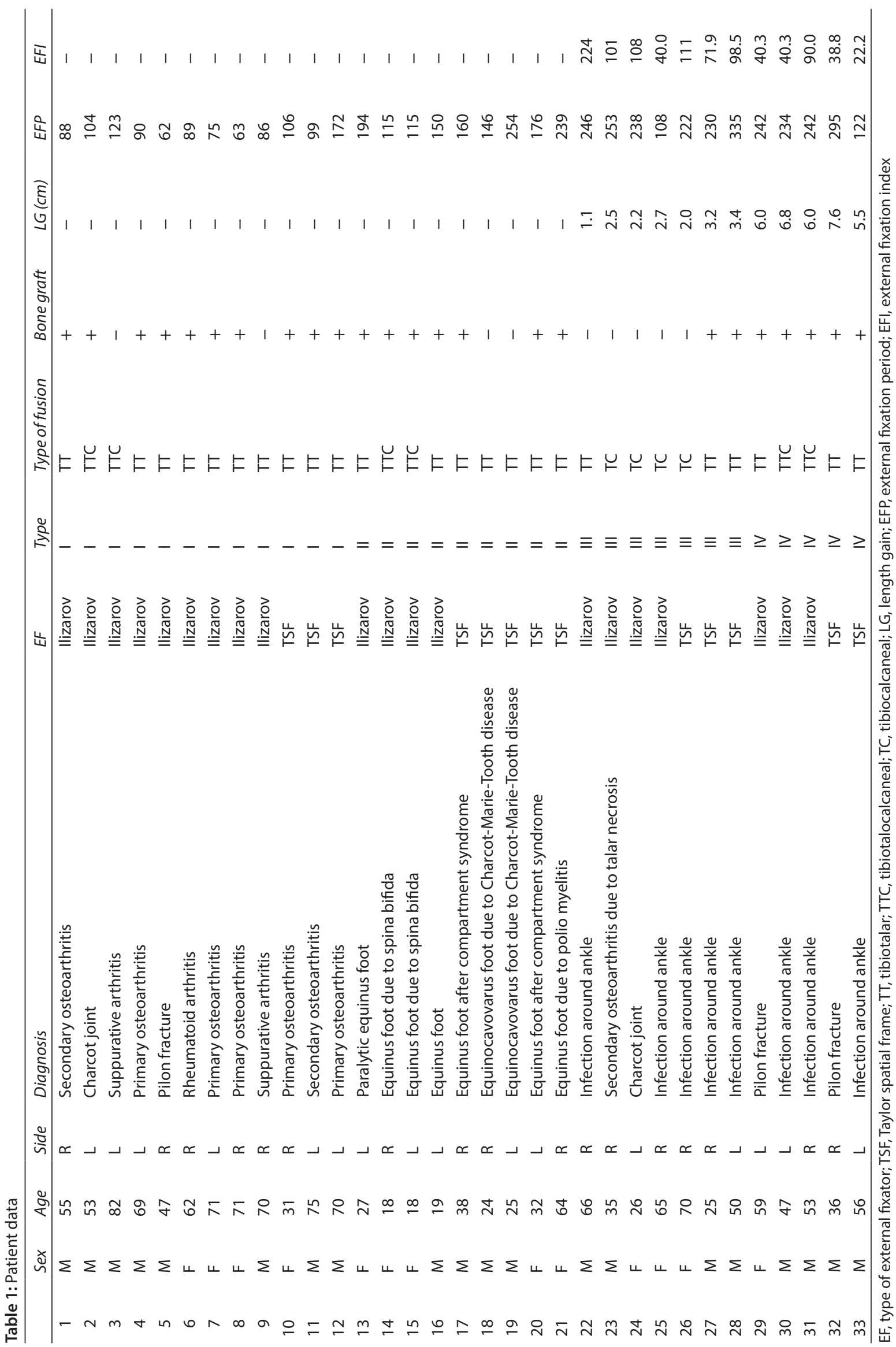




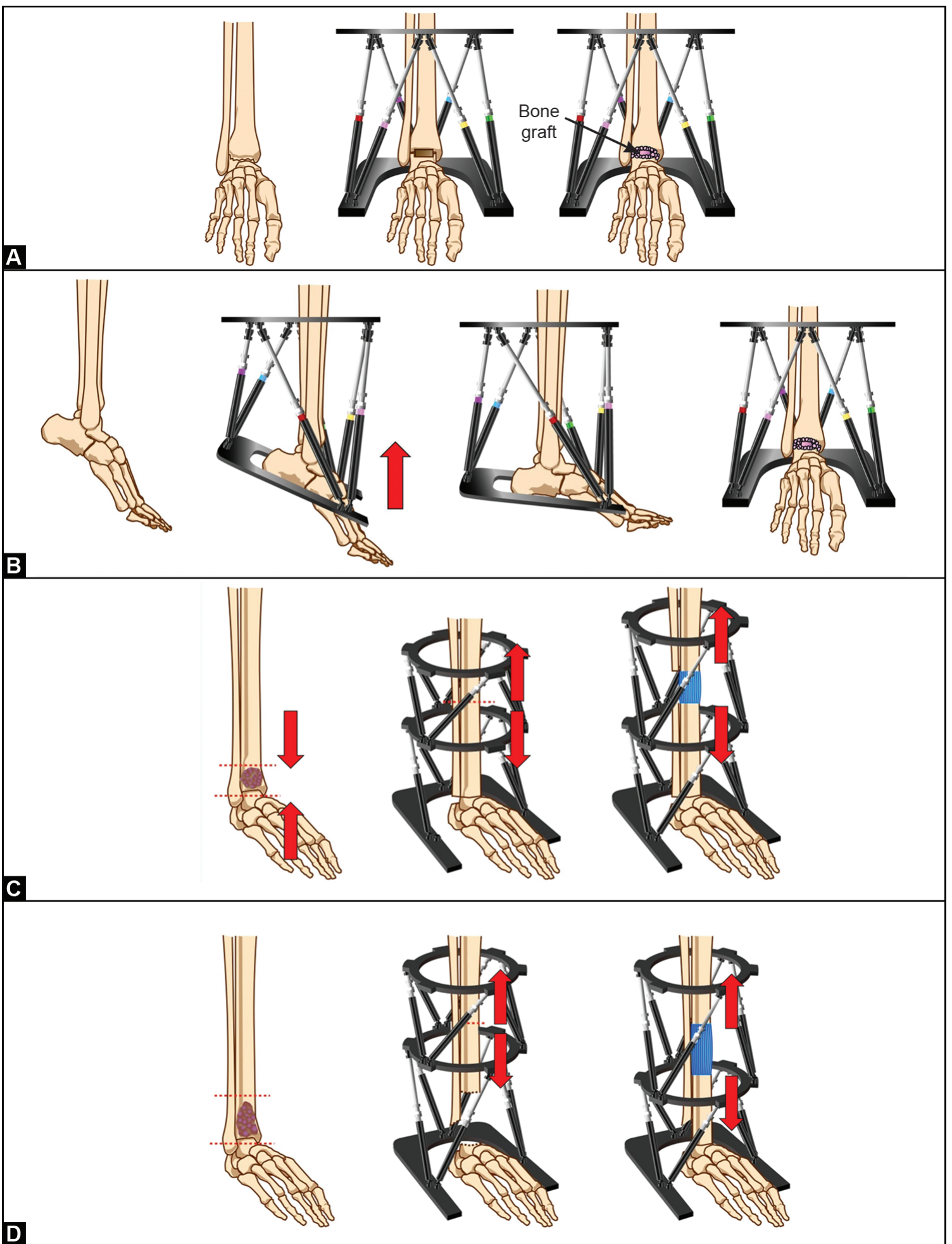

Figs 1A to D: Classification of the surgical strategies (procedures): (A) Ankle arthrodesis of type l; (B) Ankle arthrodesis of type II; (C) Ankle arthrodesis of type III; (D) Ankle arthrodesis of type IV

have also be conducting a conversion procedure to plate fixation after the initial lengthening by external fixation for type III and type IV procedures (two ankles).

\section{Operative Technique}

We aimed to obtain a neutral position at ankle fusion which is plantigrade and slightly external rotated in all patients. We classify the operative methods into four types (Fig. 1) based on the presurgical characteristics of the ankle including the presence of bone defect and deformity (Table 2).

\section{Type I (Fig. 1A)}

The ankle has no or little deformity which can be corrected acutely and there is no bone defect. The operative technique is to use an 
Table 2: Indication of each type of ankle arthrodesis using an external fixator

\begin{tabular}{lll}
\hline & Deformity & Defect \\
\hline Type I & small or - & - \\
Type II & + & - \\
Type III & + or - & + \\
Type IV & + or - & ++ \\
\hline
\end{tabular}

anterior approach, curette the articular cartilage surfaces off the ankle joint and preserve the posterior wall of joint if the ankle is without infection. In contrast, the entire surface of ankle joint is removed if there is infection. After curettage, further removal is continued to make space for bone graft from the iliac crest and to enable correction of any deformity before securing the position with an external fixator and inserting the autogenous graft (11 ankles).

\section{Type II (Fig. 1B)}

The patient has a severe deformity which cannot be corrected acutely but there is no bone defect, e.g., in the paralytic foot with severe equinus deformity. The type II ankle arthrodesis procedure involves applying an external fixator with or without soft tissue release depending on the severity of deformity. Gradual correction using the external fixator is performed until correct alignment is obtained. At this point of treatment, a second intervention as that done in a type I ankle arthrodesis is performed using the same external fixator with or without adjustment to the fixator construct at second surgery (10 ankles).

\section{Type III (Fig. 1C)}

In this ankle arthrodesis procedure there is a different strategy arising because of a bone defect in the distal tibia but the size of which is amenable to eradication by acute shortening (generally less than $5 \mathrm{~cm}$ ). There can be an associated deformity which is also corrected acutely. For example, in the patient who has defect after the debridement of an infection site at distal tibia, or one who has bone defect due to comminuted fracture. This method includes resection or curettage of pathological site at distal tibia, shortening (and correcting the deformity if needed) acutely, fixing it in the correct alignment using an external fixator and restoring leg length equality through limb lengthening in the proximal tibia (7 ankles).

\section{Type IV (Fig. 1D)}

This surgical strategy is used when there is a bone defect in the distal tibia which cannot be eliminated by acute shortening largely due to the size of the defect (generally more than $5 \mathrm{~cm}$ ) or from the presence of soft tissue problems. There can be concomitant shortening already present in that lower limb or the presence of a deformity. This procedure will include a resection or curettage of pathological site in the distal tibia followed by an osteotomy at proximal site for bone transport. Ankle fusion is performed at the docking site when the bone transport or limb lengthening is complete (5 ankles).

\section{Results}

The average external fixation periods were 96 days in type I, 60 days for mobilisation and 112 days for arthrodesis in type II, 253 days without plate conversion and 122 days with plate conversion in type III, and 254 days without plate conversion and 108 days with plate conversion in type IV. The mean length gain was $2.4 \mathrm{~cm}$ in type III and $6.4 \mathrm{~cm}$ in type IV. The average external fixation index (EFI) was 119 days/cm without plate conversion and 40.0 days/cm with plate conversion in type III. In type IV procedures this was 52.4 days $/ \mathrm{cm}$ without plate conversion and 22.2 days $/ \mathrm{cm}$ with plate conversion (Figs 2 to 5 ).

At the final follow-up, all patients had achieved a secure ankle fusion and were able to walk with mild or no pain. There were complications. A re-fracture occurred in three patients and this was treated by a re-application of the external fixator or with screw internal fixation. A deformity at the lengthening site occurred in one patient and this was treated with revision of external fixator. A delayed union at the fusion in one patient was treated with conversion to internal fixation. There was infection at fusion site in one patient and this was treated with curettage and artificial bone graft containing antibiotics.

\section{Discussion}

In this study, we used different strategies for ankle fusion depending on the presenting clinical and radiological features. Successful ankle fusion of all 33 ankles were achieved and with good clinical results. Owing to the need to alter the surgical procedure depending on the characteristics of the clinical problem, we have classified operation methods of ankle arthrodesis with an external fixator. This classification can help with the correct choice of strategy for ankle arthrodesis with an external fixator based on the patient's condition and pathogenesis.

The literature has many reports of different techniques of ankle arthrodesis even for patients who have no or small deformity, similar to those in this sample who have had our type I ankle arthrodesis. We acknowledge that there are many kinds of methods in terms of approach, fixation, and bone graft and the lack of one "gold standard" is because most of the methods described report a good result. Recently ankle arthrodesis by using ankle arthroscopy and percutaneous screw fixation is gaining popularity from the nature of minimal invasiveness. ${ }^{1-3,14}$ In addition to that, ankle arthrodesis by using new types of internal fixation locking plates is also popular due to the behavior of the implant as an internal fixator. ${ }^{15-18}$ In contrast, ankle arthrodesis with an external fixator tends to be avoided because the procedure is more complicated and patients are uncomfortable with the fixator for prolonged periods of time. This disadvantage has to be weighed against the merits which include early weight-bearing (which induces faster bone union), the ability to use this method of fixation in cases with infection and disuse bone atrophy. Additionally, there is the extra ability to make fine adjustments to the arthrodesis in order to obtain the optimum position even after operation.

Controversy and surgeon preference will factor in choosing the technique of ankle arthrodesis with each method having a balance of merits and demerits. Despite this, selecting an appropriate method should deliver good results if the patients have no or small deformity, no bone defect, and no infection. On the other hand, there are many patients who cannot be treated with internal fixation. For example, patients who have severe deformity, large bone defects, and established extensive deep infection. For these patients, an external fixator would be first and appropriate choice. Severe deformity could be treated with our type II procedure, whereas large bone defects and severe infection with our type III or IV methods. If patients with severe deformity are treated by an acute correction and ankle arthrodesis, 

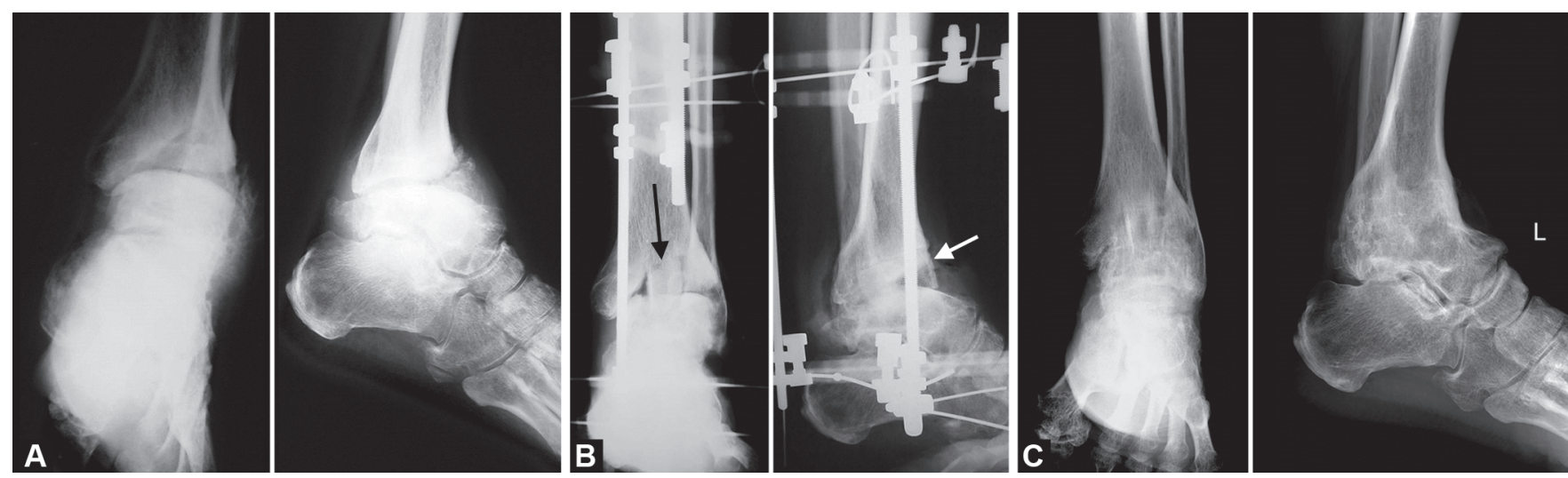

Figs 2 A to C: Case 1 (type I ankle arthrodesis). A 53-year-old male with Charcot ankle joint due to incomplete spinal lesion: (A) Preoperative radiographs. The ankle joint was destroyed and had severe instability; (B) Postoperative radiographs. Iliac bone graft was performed (arrow); (C) Radiographs at four years and six months after the operation. Solid ankle fusion was obtained
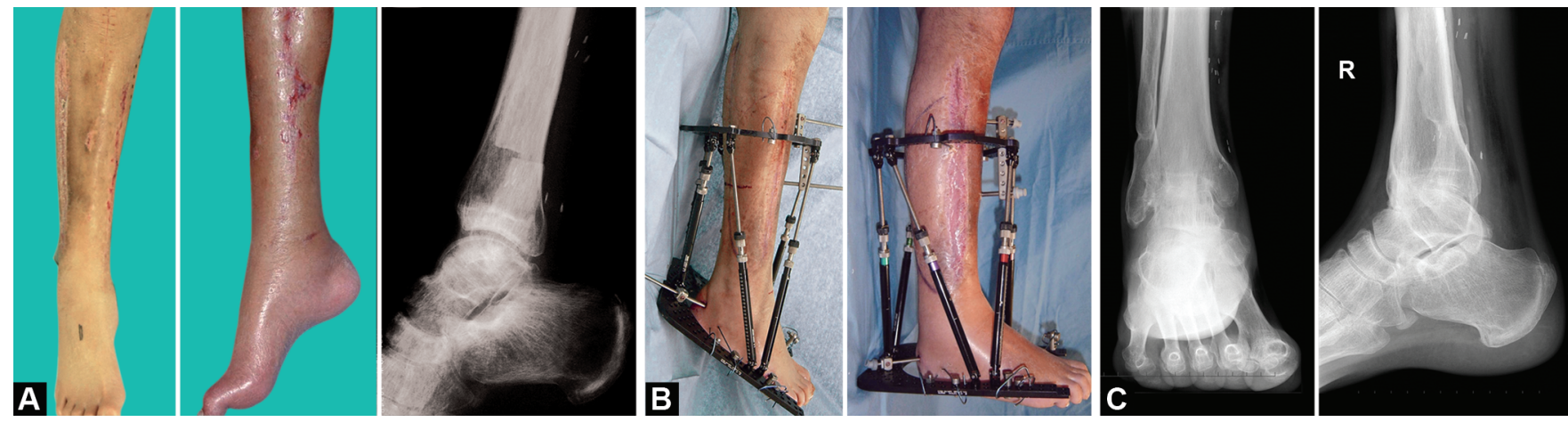

Figs $3 \mathrm{~A}$ to C: Case 2 (type II ankle arthrodesis). A 38-year-old male with an equinus foot due to a compartment syndrome: (A) Preoperative radiographs and clinical photography. A severe equinus foot was observed; (B) External fixator was applied and equinus foot was gradually corrected. Before correction (left), and after correction (right); (C) Radiographs at 3 years after the operation. Good alignment and firm ankle fusion were attained
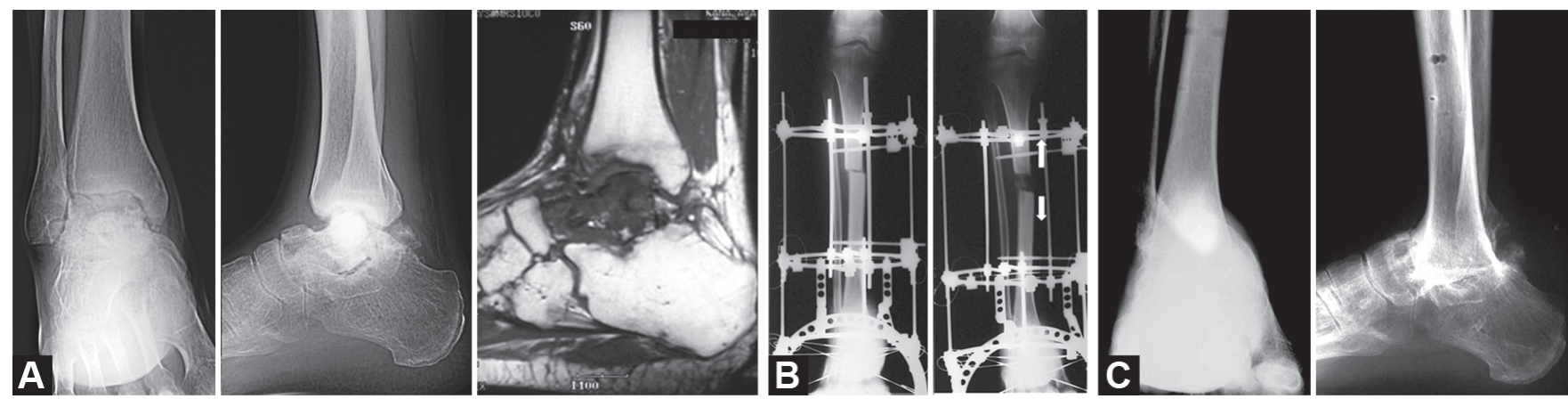

Figs 4A to C: Case 3 (type III ankle arthrodesis). A 35-year-old male with secondary osteoarthritis due to an avascular necrosis of talus: (A) Preoperative radiographs and MRI. Necrosis and destruction of the talus were observed; (B) Postoperative radiograph (left). The necrotic talus was resected and the limb shortened acutely to get ankle fusion, and osteotomy for lengthening was performed at a proximal site. Radiograph during lengthening (right); (C) Radiographs at 3 years after the operation. Solid talocalcaneal fusion was observed

this would necessitate a large bone resection that may lead to limb length discrepancy and potential issues with neurovascular tension and skin closure. By using an external fixator, severe deformity can be treated gradually and such complications be avoided. Once good alignment is obtained, the surgeon can then choose their favourite method for ankle arthrodesis. We choose the type I method because we can use same external fixator and continue with patient mobilisation.
The type III and type IV procedures are for patients who have deformities, large bone defects, and severe infection; these techniques allow for soft tissue defects to be covered by shortening, limb length discrepancies corrected by limb lengthening, and deformities gradually removed. Minematsu showed that distraction osteogenesis induces a 2 or 3 times increase of blood flow which helps subsidence of infection and stimulates of bone union at the ankle arthrodesis site. ${ }^{19}$ 

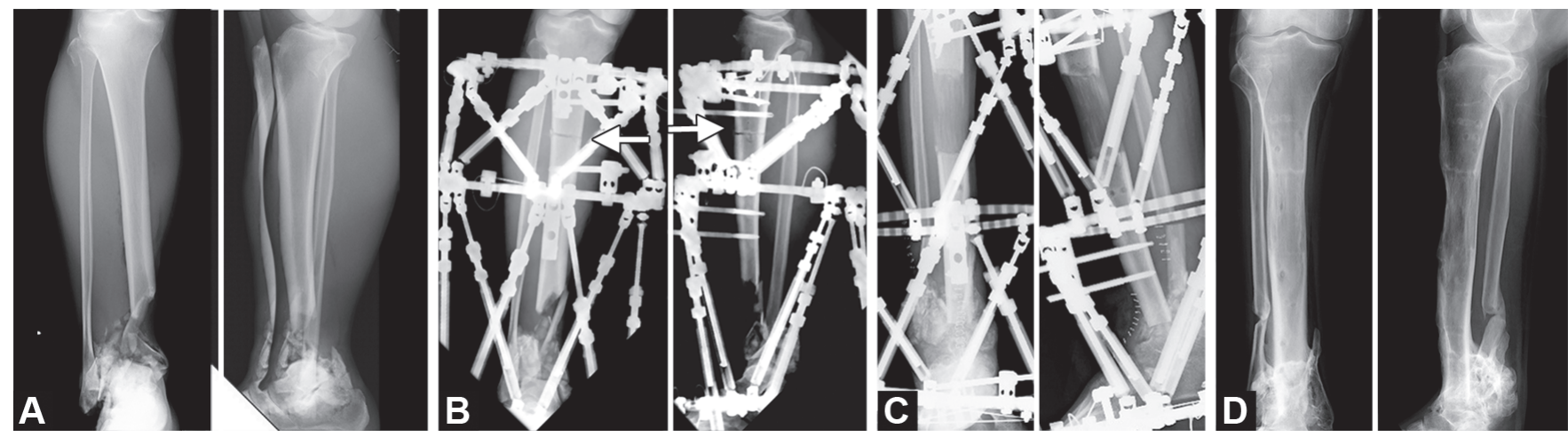

Figs 5A to D: Case 4 (type IV ankle arthrodesis). A 36-year-old male with an $8 \mathrm{~cm}$ bone defect after an open pilon fracture. (A) Radiographs at the accident. A bone defect of $8 \mathrm{~cm}$ at distal tibia was noted; (B) Postoperative radiographs. Osteotomy (arrow) was performed for bone transport after the operation; (C) Bone graft at docking site was performed after completion of bone transport; (D) Radiographs at 6 years after the operation. Firm ankle fusion was attained

Flowchart 1: Algorithm of ankle arthrodesis using an external fixator

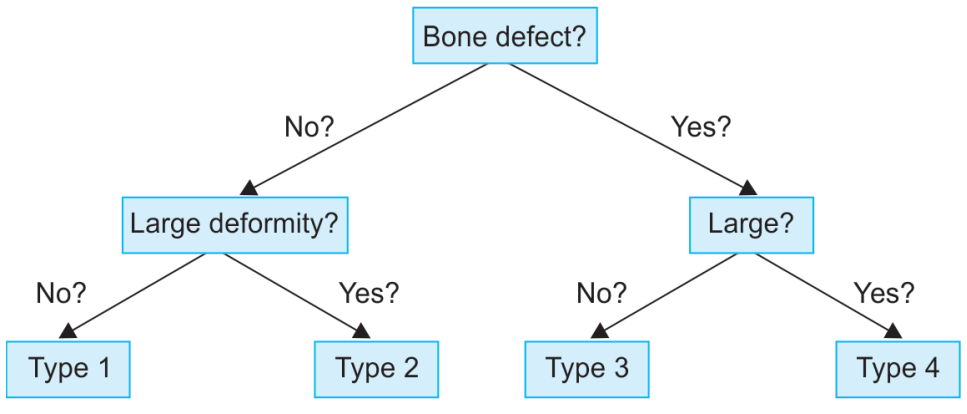

There is increasing number of publications on the ankle arthrodesis with using a circular external fixator. Zarutsky reported that 33 out of 43 difficult cases achieved a solid fusion and the major complication rate was $51.2 \% .{ }^{4}$ Eylon demonstrated that all 17 cases achieved a solid ankle fusion without any additional procedures or severe complications. ${ }^{5}$ Salem showed that all 22 cases attained a solid ankle fusion but complications were seen in 11 cases. ${ }^{6}$ Fragomen showed that fusion was achieved in 76 of 91 patients, and smokers should be warned of the high risk of nonunion and that it is recommended they quit smoking. ${ }^{10}$ Onodera reported a $100 \%$ fusion rate out of 43 ankles without major complications. ${ }^{12}$ We have used TSF (a hexapod circular external fixator) since 2003 as we find it makes achieving any correction after the operation easier than the classic Ilizarov external fixator. Surgeons who have been unwilling to use a classic circular external fixator for ankle arthrodesis find they are able to use the TSF. ${ }^{20}$ We attained solid fusions in all 33 feet with some additional procedures. Most papers published describing ankle arthrodesis with using an external fixator have showed special benefits when used for difficult cases such as revision, deformity, bone defect, and infection. However, most of these papers report on ankle arthrodesis using an external fixator but without deformity correction or limb lengthening, both facilities which are most usefully done with an external fixator. In this paper, by classifying the operative methods of ankle arthrodesis with an external fixator into 4 groups, we have described absolute or relative indications for use of an external fixator and how to match the surgical technique for difficult cases. This classification is effectively an algorithm for ankle arthrodesis when using an external fixator to enable easier selection of the optimum technique (Flowchart 1) .
In conclusion, ankle arthrodesis performed with an external fixator can be a very useful technique and has special merits when used for difficult cases such as those with deformity and bone defects. We have classified the technique into four types, thereby enabling to surgeon to select the optimum procedure for the combination of clinical and radiological characteristics that determine the clinical problem at the ankle. We expect this method of classification to be helpful, particularly for complex cases.

\section{Ethics Approval}

All study participants provided informed consent, and the study design was approved by an ethics review board.

\section{Consent for Publication}

All author gives their consents for information about themself to be published in Strategies in Trauma and Limb Reconstruction journal.

\section{Availability of Data and Material}

The datasets during and/or analysed during the current study available from the corresponding author on reasonable request.

\section{References}

1. Jerosch J, Steinbeck J, Schroder M, et al. Arthroscopically assisted arthrodesis of the ankle joint. Arch Orthop Trauma Surg 1996;115(34):182-189. DOI: $10.1007 / \mathrm{bf00434550.}$

2. Yasui $Y$, Hannon CP, Seow D, et al. Ankle arthrodesis: A systematic approach and review of the literature. World J Orthop 2016;18(11):700708. DOI: $10.5312 /$ wjo.v7.i11.700. 
3. Woo BJ, Lai MC, Ng S, et al. Clinical outcomes comparing arthroscopic vs open ankle arthrodesis. Foot Ankle Surg 2019;19:30100-30106. DOI: 10.1016/j.fas.2019.06.004.

4. Zarutsky E, Rush SM, Schuberth JM. The use of circular wire external fixation in the treatment of salvage ankle arthrodesis. J Foot Ankle Surg 2005;44(1):22-31. DOI: 10.1053/j.jfas.2004.11.004.

5. Eylon S, Porat S, Bor N, et al. Outcome of Ilizarov ankle arthrodesis. Foot Ankle Int 2007;28(8):873-879. DOI: 10.3113/FAI.2007.0873.

6. Salem KH, Kinzl L, Schmelz A. Ankle arthrodesis using Ilizarov ring fixators: A review of 22 cases. Foot Ankle Int 2006;27(10):764-770. DOI: $10.1177 / 107110070602701002$.

7. Wallace SJ, Liskutin TE, Schiff AP, et al. Ankle fusion following failed initial treatment of complex ankle fractures in neuropathic diabetics. Foot Ankle Surg 2020;26(2):189-192. DOI: 10.1016/j.fas.2019. 01.010 .

8. Badahdah HM, Zgonis T. Ankle arthrodiastasis with circular external fixation for the treatment of posttraumatic ankle arthritis. Clin Podiatr Med Surg 2017;34(4):425-431. DOI: 10.1016/j.cpm.2017.05.001.

9. El-Alfy B. Arthrodesis of the ankle joint by llizarov external fixator in patients with infection or poor bone stock. Foot Ankle Surg 2010;16(2):96-100. DOI: 10.1016/j.fas.2009.06.004.

10. Fragomen AT, Borst E, Schachter $\mathrm{L}$, et al. Complex ankle arthrodesis using the llizarov method yields high rate of fusion. Clin Orthop Relat Res 2012;470(10):2864-2873. DOI: 10.1007/s11999-012-2470-9.

11. Khanfour AA. Versatility of llizarov technique in difficult cases of ankle arthrodesis and review of literature. Foot Ankle Surg 2013;19(1):42-47. DOI: 10.1016/j.fas.2012.10.001.
12. Onodera T, Majima T, Kasahara Y, et al. Outcome of transfibular ankle arthrodesis with llizarov apparatus. Foot Ankle Int 2012;33(11):964968. DOI: 10.3113/FAI.2012.0964.

13. Matsubara $\mathrm{H}$, Tsuchiya $\mathrm{H}$, Takato $\mathrm{K}$, et al. Correction of ankle ankylosis with deformity using the Taylor spatial frame: A report of three cases. Foot Ankle Int 2007;28(12):1290-1294. DOI: 10.3113/FAI.2007.1290.

14. Paremain GD, Miller SD, Myerson MS. Ankle arthrodesis: results after the miniarthrotomy technique. Foot Ankle Int 1996;17(5):247-252. DOI: $10.1177 / 107110079601700502$.

15. Choi G, Ghalambor N, Nihal A, et al. Revision ankle arthrodesis with lateral cannulated angled blade plate fixation. Foot Ankle Surg 2001;7(3):187-191. DOI: 10.1046/j.1460-9584.2001.00270.x.

16. Fujimori J, Yoshino S, Koiwa M, et al. Ankle arthrodesis in rheumatoid arthritis using an intramedullary nail with fins. Foot Ankle Int 1999;20(8):485-490. DOI: 10.1177/107110079902000804.

17. Plaass C, Knupp M, Barg A, et al. Anterior double plating for rigid fixation of isolated tibiotalar arthrodesis. Foot Ankle Int 2009;30(7):631-639. DOI: 10.3113/FAI.2009.0631.

18. Colman AB, Pomeroy GC. Transfibular ankle arthrodesis with rigid internal fixation: An assessment of outcome. Foot Ankle Int 2007;28(3):303-307. DOI: 10.3113/FAI.2007.0303.

19. Minematsu K, Tsuchiya H, Taki J, et al. Blood flow measurement during distraction osteogenesis. Clin Orthop 1998;347(347):229-235. DOI: 10.1097/00003086-199802000-00028.

20. Thiryayi WA, Naqui Z, Khan SA. Use of the Taylor spatial frame in compression arthrodesis of the ankle: A study of 10 cases. J Foot Ankle Surg 2010;49(2):182-187. DOI: 10.1053/j.jfas.2009.05.015. 